\title{
Promoting Entrepreneurial Skills through Senior Design Projects
}

\section{Ms. Nabila A. Bousaba, University of North Carolina, Charlotte}

Nabila (Nan) BouSaba is a faculty associate with the Electrical and Computer Engineering Department at the University of North Carolina at Charlotte since 2008; she is the senior design instructor for the department, courses taught include Basic Circuit for non- majors, and Technology Innovation and Entrepreneurship course at UNC Charlotte. Nan Earned her BS and Master Degrees in Electrical Engineering $(1982,1986)$ from North Carolina Agricultural \&Technical State University. She mentored Departmental sponsored projects such as UNCC Parking team, IEEE Hardware competition teams, industry sponsored projects from Microsoft and EPRI, NASA teams and special Innovation and Entrepreneurship teams. She published and presented papers in ASEE conferences in June 2009, 2010, 2011 and 2014. She published paper in IEEE conference in 2013. Prior to her current position at UNC- Charlotte, she worked for IBM (15 years) and Solectron ( 8 years) in the area of test development and management.

\section{Dr. James M. Conrad, University of North Carolina, Charlotte}

James M. Conrad received his bachelor's degree in computer science from the University of Illinois, Urbana, and his master's and doctorate degrees in computer engineering from North Carolina State University. He is currently a professor at the University of North Carolina at Charlotte. He has served as an assistant professor at the University of Arkansas and as an instructor at North Carolina State University. He has also worked at IBM in Research Triangle Park, North Carolina, and Houston, Texas; at Ericsson/Sony Ericsson in Research Triangle Park, North Carolina; and at BPM Technology in Greenville, South Carolina. Dr. Conrad is a Professional Engineer, Senior Member of the IEEE and a Certified Project Management Professional (PMP). He is also a member of ASEE, Eta Kappa Nu, and the Project Management Institute. He is the author of numerous books, book chapters, journal articles, and conference papers in the areas of embedded systems, robotics, parallel processing, and engineering education. 


\title{
Promoting Entrepreneurial Skills through Senior Design Projects at the University of North Carolina at Charlotte
}

\begin{abstract}
Two faculty from the Electrical and Computer Engineering Department at the University of North Carolina at charlotte received a grant from VentureWell to develop a course in innovation and entrepreneurship. They offered the course in the spring 2013, spring 2014 and spring 2015 semesters. This course consisted of graduate and undergraduate students from several disciplines working on multiple projects; each project was unique, formed out of student or faculty ideas.
\end{abstract}

The faculty teaching this course developed a strategy to nourish the innovation and entrepreneurship in young engineer by allowing all engineering majors to register for the course and by forming multidisciplinary teams that worked on the innovation of the idea, developed an executive summary of the project and looked into the financial support of the invention. Each team had to analyze the opportunity at hand, provide a thorough market analysis, and write a report about the project (from inception to commercialization). Students on each team were encouraged to continue to work together in the College of Engineering Senior Design I and Senior Design II courses with the intent of them being able to commercialize the design.

Part of the faculty effort was to build and promote a culture of innovation among engineering students; therefore as a follow up from the course offering in the spring 2013 the faculty supported two projects during their capstone senior design courses for the fall 2013-spring 2014 semesters with a strong plan for commercialization of the product. These students were motivated, self-driven and excited about their projects and the possibility of launching a business successfully by using our program, and taking advantage of the resources available to them from our University's Office of Technology Transfer. This support allowed these two teams to design and prototype the product during the fall 2013 and spring 2014 semesters. These two teams received multiple cash awards while competing in the State of North Carolina Social Entrepreneurship Conference and the Ventureprise business competition. One team built a company which is still active even after the participants graduated with their Baccalaureate degrees. Thus far the faculty have supported four entrepreneurial teams in the capstone senior design courses.

While the entrepreneurship course gives a chance for our students to work with a faculty on the development of a new product, linking it to the capstone senior design course strengthens the foundation for our engineering students to embark on new opportunity when feasible. This combination helped our students identify opportunities to implement all ideas, helped individual student learn about managing business growth, and provided methods of using critical thinking.

The Technology Innovation and Entrepreneurship course linked with our senior design capstone courses empowers our graduates to confront challenging business cases and to seek solution from a business perspective. Our goal is to encourage our engineering students to work with business students from the inception of an entrepreneurship project until commercialization. This paper describes in detail the successes of these entrepreneurial Senior Design teams. 


\section{Introduction and Literature Review}

Past research shows the need for an educational shift in the general engineering curricula from a purely technical focus to one that will add entrepreneurial skills to complement their undergraduate engineering major. ${ }^{1}$ Angela Shartrand, et al. ${ }^{2}$, in "Technology Entrepreneurship programs in U.S. Engineering Schools: An Analysis of programs at the undergraduate level" examined programs and courses offered at 340 ASEE member schools in the U.S. Their research showed that "entrepreneurship education is available in at least half of the engineering programmed examined and has been integrated within the engineering program in approximately $25 \%$ of these programs" ${ }^{2}$. We asked ourselves the question "do engineer need entrepreneurship skill?” Based on the article by Ochs, et al. ${ }^{3}$, we read that “The engineer as inventor is certainly not new.

Since we recognized that many innovative products that we enjoy today were created by engineers"4; faculty from the Electrical and Computer Engineering Department at the University of North Carolina at Charlotte sought a mechanism to encourage innovation by students. We were attracted by the availability of funds from VentureWell, formerly known as National Collegiate Inventors and Innovators Alliance (NCIIA) for Universities ${ }^{2,5}$ in the support of course development in Innovation and entrepreneurship. In the fall of 2011 the faculty researched other engineering colleges with entrepreneurship courses, prepared and submitted a proposal for a grant from VentureWell to support a new course in entrepreneurship. They received a grant in the spring of 2012 to support the activity of developing this course while supporting innovation in the college. Sullivan, et al. ${ }^{6}$, indicated that a course in innovation will be considered successful if the students experience the process of invention and innovation by saying "understanding the customer and market are critical for an invention to find a niche"6 students should understand that "their inventions must reach the market in order to have an impact on the world"6.

\section{Faculty Offered a Course in Technology Innovation and Entrepreneurship}

Two faculty developed the course material and offered the course for the first time in the spring 2013 semester; enrollment was nineteen students (sixteen undergraduate and three graduate students) ${ }^{1}$. We formed five project teams where each group worked on an innovative technical product. A part of the course required all teams to submit an internal VentureWell "E-Team" proposal; group presented their proposal in an oral presentation defending their approach to the faculty and class. The instructors of the class selected the three top projects and assist the teams by submitting their proposals to the VentureWell E-Team Competition in May 2013. None of these projects were funded; but the teams received positive review. We followed up to that by funding the top two teams to design and prototype the product during the fall 2013 and spring 2014 in their senior design capstone courses.

The Technology Innovation and Entrepreneurship course was designed to be valuable for engineering students who plan to embark on the process of innovation and entrepreneurship while practicing in the field of engineering. Entrepreneurship concepts introduced in this course helped students identify opportunities to implement these ideas. This course helped students learn how to manage business growth, and provide them with the methods and skills to use critical thinking. Through lectures, case studies, reading materials and potential projects that 
cover ventures growth, this course provided students with the necessary background to successfully identify business opportunity, and to embark on forming a new enterprise. In this course we introduced the students to many concepts such as identifying business opportunities, finding innovative and competitive strategies and how to submit for a small business grant or other types of grants. At the beginning of the semester we solicit entrepreneurship ideas from the students in the class, we work with the students and the UNC Charlotte Office of Technology Transfer $^{7}$ on the Intellectual property for the idea. In the spring 2013 semester we formed six teams where students worked together on these projects; one team, the conservatory team, worked in parallel on the prototype of the project (see Figures 3a and 3b) in the Senior Design II capstone course.

\section{Promoting a Culture of Innovation by Supporting Projects in Senior Design Capstone Courses}

Our foray into entrepreneurial senior design projects started with a student idea - can students design and build a dryer vent-crawling robot that is both innovative and marketable. The students successfully designed and prototyped a device ${ }^{8}$. The business concept was very well received by the entrepreneurial community in our town - it won second prize for student-lead ideas. Unfortunately, since there was no financial support for a rugged prototype, the idea was not pursued.

To build and promote a culture of innovation the faculty decided to support senior design projects from the course grant. We followed the UNC Charlotte senior design capstone course ${ }^{9,10}$ process of posting the project description on the course website. Examples of these can see at references 11 through 15 . This methodology provided a chance to all our senior engineering students to read these entrepreneurship topics and select them to be from their top five senior design project choice if they wish. Each semester we selected additional students to join the each group.

The first entrepreneurship project that received support from the course grant was in the fall 2012. The design team consisted of five multidisciplinary (two computer, one electrical and two mechanical) students working together on designing a system that can create an environment that will autonomously grow plants utilizing various types of sensors, the sensors and controls take the human factor out of the hydroponics process and allows for the plants to be grown in optimal growing conditions ${ }^{11}$. The first goal of this project was to create a design and demonstrate a proof of concept of the design in the $2^{\text {nd }}$ semester of this capstone sequence. This design can be utilized by a group of hobbyists (that don't have the room or time for a garden) as well as large corporation looking for more efficient, cheaper, autonomous way to monitor and grow their products. This system uses a database server, control system, and a Mobile Notification System (MNS). The server is used for data storage and hosting the MNS. The control system incorporates the Arduino microcontroller board for processing sensor measurements. Sensors are used to monitor $\mathrm{pH}$, conductivity, and temperature of the environment. Peripherals attached to the control system are used to drive the sensor measurements. The mobile notification system utilizes JAVA, PACHE, and PYTHON languages. The designed control of the system uses the data reading to constantly maintain and balance the environment without any human interaction. The system incorporates a unique alert system via SMS if any sensors failed. The team 
completed the design by December 2012, and delivered a full prototype by the end of the spring semester of 2013 as seen in Figure 1 (a) and (b) below. We met our second goal by taking a subset of students from this team and formed a new group. This new team worked on the commercializing aspect of this project while attending our new course of Technology Innovation and Entrepreneurship in the spring 2013 semester.

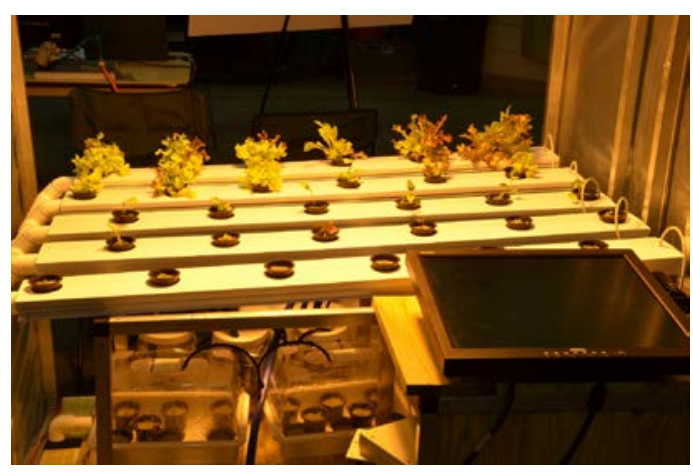

Figure 1: (a) Nursery of the plants

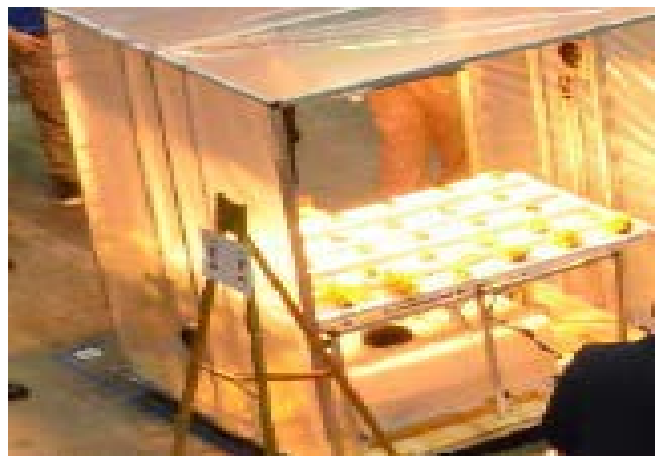

(b) The actual prototype at the Exposition

The second team to receive support during their capstone courses was the Integrated Living Assistant (ILA, also known as the company Red Wire logic) team. This team consists of four Electrical Engineering students that attended the technology innovation and Entrepreneurship course in the spring of 2013. These students came up with the idea by themselves during the class, they were granted the Intellectual Property (IP) right to their idea from our University office of technology transfer. The faculty offering the course encouraged these four students to work on their idea during their senior design capstone courses with three thousand dollar fund from the faculty grant in support of the project prototype.

The Integrated Living Assistant project is a smart, residential solution capable of power control and monitoring. It is an innovative technology that will feature remote or autonomous control over household devices and monitor power consumption in real time $\mathrm{e}^{12}$.

The main function of ILA is the combination of artificial intelligence with a progressive home automation system as seen in Figure 2 below.

The intelligent operating system facilitates the interaction with the home, it uses machinelearning algorithms and remote responses to achieve autonomous control. ILA consists of multiple remote modules with unique network identifiers installed throughout the home. These remote modules communicate with a single centrally located base station.

The base station, in turn will communicate with the home computer, tablet, or other Internetconnected devices. Communication between ILA's base station and remote modules present realtime statistics at the fingertips of the user enabling them to track and control energy usage. The tracking and statistics could be accessed either with the home computer or across the Internet with an application-based program on any smart device. The user also has the ability to set up device "moods" that can occur at desired times or when certain conditions are met. These "moods" are a key aspect of the system artificial intelligence. 


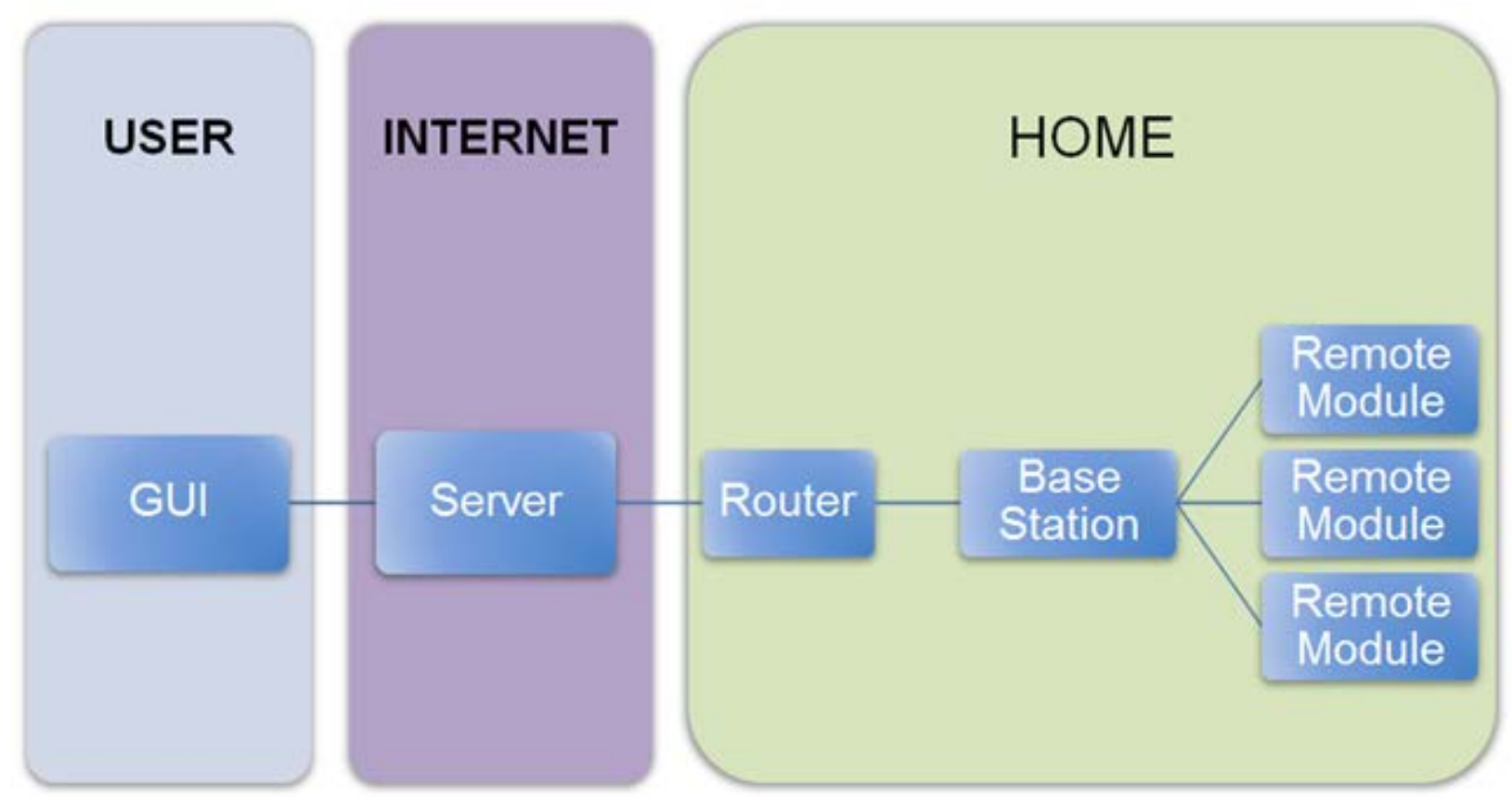

Figure 2 Complete ILA systems (figure borrowed from student final report)

A functional prototype that consists of four fully functional prototype Remote Modules and one prototype Base Station were presented in our spring 2014 Senior Design Capstone exposition.

The Integrated Living Assistance team received the first prize award out of sixty nine teams in our Senior Design Capstone Exposition. The team continued after graduation to work on the commercialization process of the product and they have been successful in selling a portion of the business to an existing company.

The Solar Traffic light team was the third team to receive support during the senior design capstone courses. A Mechanical Engineer student with Dual Major Electrical and Computer Engineering student worked on the commercialization of this idea in the Technology and Innovation course, the faculty followed up by posting the project scope on the senior design website as seen in reference 13 to advertise the project description and to add three students to the project.

Three students (one Electrical, Mechanical and Computer) were added to the team to work on the prototype of the project. This group of students completed the design in the fall 2013, assembled and tested the prototype in the spring 2014, Figure 3 (a) and (b) below borrowed from the team's report showed a picture of the actual prototype.

This prototype will help cities solve the problem of power outages in the aftermath of natural disasters, and will help under-developed countries to support traffic order. This solution of a portable solar-powered traffic light that can be easily integrated to new environment is economical with excellent performance. 

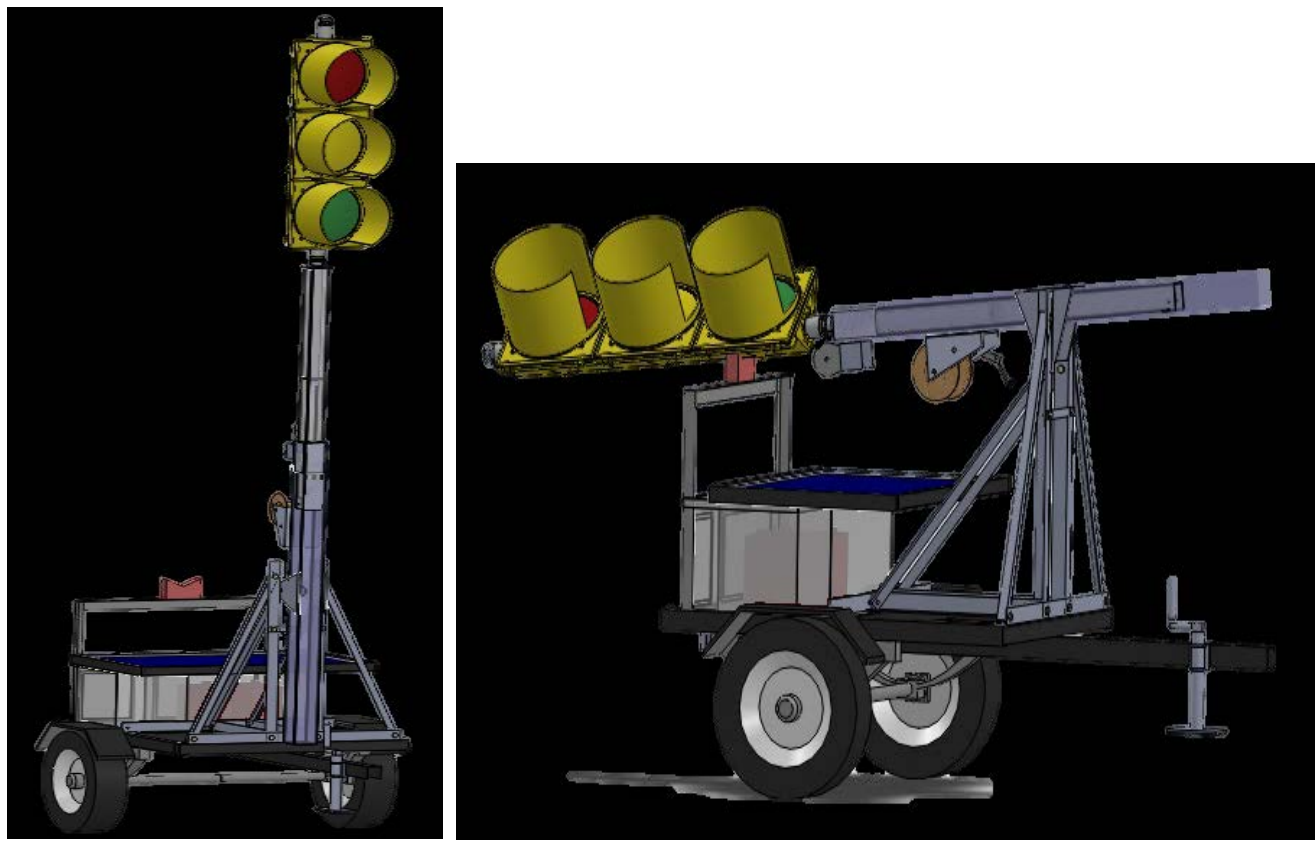

Figure 3: (a) Solar traffic light prototype

(b) Horizontal Pole Orientation for transportation

The smart Tennis racket team with energy saving capability was the fourth entrepreneurship project to receive support during senior design from the VentureWell grant. This project was generated by a student with passion to tennis, he worked on the project during the entrepreneurship course in the spring 2014, the idea sounds feasible and with potential success therefore the faculty posted the project scope on the senior design website as shown in reference 14 to add additional student to the project, the project is currently in the second phase of senior design, the team is working on the prototype, the team consist of three multidisciplinary students one from each of the following discipline Electrical, Mechanical and Computer Engineering.

The fifth senior design project to receive support from the VentureWell grant was the solar charger team in the spring 2015, the project scope was placed on the website as seen in reference 15. The team contain five students two Electrical, two Computer and one Mechanical Engineering student, the plan is to complete the Design by May 2015 with a second prototype by December of 2015. Two of the five students will be working on the commercialization aspect of the project during the entrepreneurship course in the spring 2015.

\section{Results and Future Plans}

The success of this program is best demonstrated by the success of the student teams. In particular, the local entrepreneurial business community has recognized these teams with financial awards. Table 1 below shows the list of Entrepreneurial Senior Design projects, their awards, and their current business status. 
Table 1: ECE Innovation \& Entrepreneurial Teams during Senior Design Project

\begin{tabular}{|c|c|c|c|}
\hline $\begin{array}{l}\text { Name of the } \\
\text { team }\end{array}$ & $\begin{array}{c}\text { Received } \\
\text { VentureWell grant } \\
\text { support? } \\
\end{array}$ & Team Success & $\begin{array}{l}\text { Plan for after } \\
\text { graduation }\end{array}$ \\
\hline Pipe PRO & No & $\begin{array}{l}\text { Received first place award at SDII } \\
\text { Exposition spring } 2012 \\
\text { Received } 2^{\text {nd }} \text { place award }(\$ 2 \mathrm{~K}) \text { in } \\
\text { the Venturprise challenge spring } \\
2012 \text {. }\end{array}$ & $\begin{array}{l}\text { Business not } \\
\text { pursued }\end{array}$ \\
\hline Conservatory & $\begin{array}{l}\text { Yes. Two members } \\
\text { of the team enrolled } \\
\text { in the Innovation } \\
\text { class while also } \\
\text { enrolled in SDII }\end{array}$ & Finalist at SDII Expo spring 2013 & $\begin{array}{l}\text { Business not } \\
\text { pursued }\end{array}$ \\
\hline ILA & $\begin{array}{l}\text { Yes. All four } \\
\text { members of the team } \\
\text { enrolled in the } \\
\text { Innovation class } \\
\text { before enrolled in } \\
\text { SDI }\end{array}$ & $\begin{array}{l}\text { Received first place award at SDII } \\
\text { Exposition } 2014 \\
\text { Received } 2^{\text {nd }} \text { place award (\$2K) in } \\
\text { the Venturprise challenge fall } 2013 \\
\text { Were selected in the top } 5 \text { students } \\
\text { teams, Venturprise challenge spring } \\
2014\end{array}$ & $\begin{array}{l}\text { Four students } \\
\text { plan to work on } \\
\text { this business in a } \\
\text { small incubator at } \\
\text { PORTAL - } \\
\text { received free use } \\
\text { of space }\end{array}$ \\
\hline $\begin{array}{l}\text { Solar Traffic } \\
\text { Light }\end{array}$ & $\begin{array}{l}\text { Yes. Two members } \\
\text { of the team enrolled } \\
\text { in the Innovation } \\
\text { class before enrolled } \\
\text { in SDI }\end{array}$ & $\begin{array}{l}\text { Finalist in SDII Expo spring } 2014 \\
\text { Received first place award ( } \$ 3 \mathrm{~K}) \text { in } \\
\text { the Venturprise challenge fall } 2013 \\
\text { Received } 2^{\text {nd }} \text { place award }(\$ 2 \mathrm{~K}) \text { in } \\
\text { the State Social Entrepreneurship } \\
\text { competition spring } 2014\end{array}$ & $\begin{array}{l}\text { Two students } \\
\text { plan to work on } \\
\text { this business with } \\
\text { faculty mentors }\end{array}$ \\
\hline $\begin{array}{c}\text { Tennis } \\
\text { Racket team }\end{array}$ & $\begin{array}{l}\text { Yes. The Project } \\
\text { lead of the team } \\
\text { enrolled in the } \\
\text { Innovation class } \\
\text { before enrolled in } \\
\text { SDI }\end{array}$ & $\begin{array}{l}\text { Received } 2^{\text {nd }} \text { place award }(\$ 2 K) \text { in } \\
\text { the Venturprise challenge fall } 2014\end{array}$ & $\begin{array}{l}\text { Project in } \\
\text { Progress }\end{array}$ \\
\hline
\end{tabular}




\begin{tabular}{|c|c|c|c|}
\hline $\begin{array}{c}\text { Name of the } \\
\text { team }\end{array}$ & $\begin{array}{c}\text { Received } \\
\text { VentureWell grant } \\
\text { support? } \\
\end{array}$ & Team Success & $\begin{array}{c}\text { Plan for after } \\
\text { graduation }\end{array}$ \\
\hline $\begin{array}{c}\text { Solar } \\
\text { Charger }\end{array}$ & $\begin{array}{l}\text { Yes. Two members } \\
\text { of the team enrolled } \\
\text { in the Innovation } \\
\text { class while enrolled } \\
\text { in SDI }\end{array}$ & Project in Progress & $\begin{array}{c}\text { Project in } \\
\text { Progress }\end{array}$ \\
\hline
\end{tabular}

Sustainability is a key element for our success; we would like to continue developing new ideas and projects that will inspire new students participating in this course. We plan to continue forming teams with Innovation ideas; this will bring strong quality results. We would like to embark on a new collaboration with our Business School and or with other universities to promote Innovation and Entrepreneurship Programs. We would like to allow our engineering students to earn a certificate in entrepreneurship if they take the following four courses:

1. Technology Innovation and Entrepreneurship course ECGR4090

2. Senior Design I course ECGR 3253

3. Senior Design II course ECGR 3254

4. Managing the Start-Up (ENTR 3101) from our business school.

The technology Innovation and Entrepreneurship course linked with our senior design capstone courses and the certificate will empower our graduates to confront challenging business cases and to seek solution from a business perspective. Our goal is to get our Engineering students to work with business students from the inception of an entrepreneurship project until commercialization (from ECGR 4090 to business course ENTR 3101).

\section{Conclusion}

In summary, the offering of this course and the support to senior design projects from this grant allowed some of our students the opportunity to explore the areas of innovation and entrepreneurship. These students will start their career with an edge over other engineering students because they will be able to launch businesses successfully by using concepts learned in our program. The offering of this course provided a culture of life-long innovation in our college; it enhanced our engineering students' entrepreneurship skills. With this new course, our students will establish a foundation for a small business incubator in the region. 


\section{References}

1. Bousaba, N. and Conrad, J., “Recent Graduates’ Perspectives on Innovation and Entrepreneurship and the Creation of New Entrepreneurship Course," Proceedings from the American Society for Engineering Education Conference, June 2014.

2. Shartrand, A., Weilerstein, P., Besterfield-Sacre, M., and Golding, C., "Technology Entrepreneurship Programs in U.S. Engineering Schools: An Analysis of Programs at the Undergraduate Level,” Proceedings from the American Society for Engineering Education Conference, June 2010.

3. Ochs, J., Watkins, T., and Boothe, B., "Creating a Truly Multidisciplinary Entrepreneurial Educational Environment," Journal of Engineering Education, Volume 90, Issue 4, October 2001, pp. 577-583.

4. Standish-Kuon, T. and Rice, M., "Introducing Engineering and Science Students to Entrepreneurship: Models and Influential Factors at Six American Universities,” Journal of Engineering Education, Volume 91, Issue 1, pp. 33-39, January 2002.

5. Weilerstein, P., and Shartrand, A., "Fostering Technology Entrepreneurship in Engineering Education: Outcomes and Impacts of the NCIIA Course and Program Grants Program,” Proceedings from the American Society for Engineering Education Conference, June 2009.

6. Sullivan, J., Carlson, L., and Carlson, D., "Developing Aspiring Engineers into Budding Entrepreneurs: An Invention and Innovation Course,” Journal of Engineering Education, Volume 90, Issue 4, October 2001, pp. 571-576.

7. UNC Charlotte Office of Technology Transfer at http://research.uncc.edu/technologytransfer

8. Harris, A., Davis, J., Meeks, J., Monfort T., and Conrad, J., “Concept for a Pipe-Traversing Robot,” Proceedings of the 2012 IEEE SoutheastCon, March 2012.

9. Conrad, J., BouSaba, N., Hoch, D., Heybruck, W., Schmidt, P., and Sharer, D., “Assessing Senior Design Project Deliverables," Proceedings from the American Society for Engineering Education Conference, June 2009.

10. Conrad, J., Hoch, D., Heybruck, W., Schmidt, P., Kane, M., Thurman, L., and Skinner, F., "Working with Industry Sponsors in a Multidisciplinary Senior Design Program," Proceedings from the American Society for Engineering Education Conference, June 2008.

11. Entrepreneurship Senior Design Project Description, fall 2012 at http://srdesign.uncc.edu/sites/srdesign.uncc.edu/files/NCIIA_Conservatorypub.pdf.

12. Entrepreneurship Senior Design Project Description, fall 2013 at http://srdesign.uncc.edu/sites/srdesign.uncc.edu/files/UNCC\%20Integrated\%20Living\%20As sistant_0.pdf

13. Entrepreneurship Senior Design Project Description, fall 2013 at http://srdesign.uncc.edu/sites/srdesign.uncc.edu/files/UNCC\%20Solar\%20Traffic\%20Light.p $\underline{\text { df }}$

14. Entrepreneurship Senior Design Project Description, fall 2014 at http://srdesign.uncc.edu/sites/srdesign.uncc.edu/files/projects/UNCC\%20NCIIA\%20Hit\%20 Pro.pdf

15. Entrepreneurship Senior Design Project Description, spring 2015 at http://srdesign.uncc.edu/sites/srdesign.uncc.edu/files/projects/UNCC\%20Solar\%20Charging \%20Station_0.pdf 